\title{
A psiquiatria transcultural no Brasil: Rubim de Pinho e as "psicoses" da cultura nacional
}

Transcrição e adaptação para texto escrito, introdução e notas por: Paulo Dalgalarrondo, Silvia Maria Azevedo dos Santos e Ana Maria Raimundo Oda

Departamento de Psicologia Médica e Psiquiatria, Faculdade de Ciências Médicas, Unicamp. Campinas, SP, Brasil

Álvaro Rubim de Pinho nasceu em Manaus (1922) e faleceu em Salvador (1996). Formou-se médico pela Faculdade de Medicina da Bahia em 1945, especializando-se em psiquiatria em Salvador e São Paulo. Defendeu as teses: "Diagnóstico da psicose maníaco-depressiva", em 1955 e "As funções cognitivas dos epilépticos", em 1965. Por muitas décadas, foi o professor titular de psiquiatria da Universidade Federal da Bahia, formando e influenciando gerações de psiquiatras.

A obra de Rubim de Pinho totaliza cerca de setenta publicações de sua autoria ou co-autoria, incluindo investigações em psiquiatria transcultural, psicofarmacologia, neuropsiquiatria, psiquiatria forense e história da medicina. Alguns de seus trabalhos sobre psiquiatria cultural e antropologia das doenças mentais foram: "Aspectos socioculturais das depressões na Bahia, 1968"; "Tratamentos religiosos das doenças mentais em um bairro pobre de Salvador, 1976"; "Social and medical aspects of the use of Cannabis in Brazil, 1973"; "Aspectos históricos da psiquiatria folclórica no Brasil, 1982" e "O cultural e o histórico no campo do delírio, 1983".

Em entrevista a Renato Alarcón (1990), * Rubim de Pinho afirmou que seus principais mestres foram Luiz Cerqueira, que o influenciou no estudo das dimensões sociais da doença mental, e o professor catedrático Nelson Pires, que o ensinou a importância da psicopatologia. Além disso, estudou com afinco as obras de Raimundo Nina Rodrigues, particularmente aquelas dedicadas aos transtornos mentais coletivos, e de Arthur Ramos que, na década de vinte, realizou estudos detalhados sobre os estados de possessão do Candomblé, considerados fenômenos culturais, diferenciando-os claramente dos transes histéricos, considerados fenômenos psicopatológicos.

Rubim de Pinho considerava fundamental chamar a atenção dos psiquiatras brasileiros sobre os fatores culturais influenciando a psicopatologia e alertava para a peculiaridade e utilidade das práticas de cura religiosa no meio brasileiro.

Sua atenção como mestre e psiquiatra revelam um clínico sensível e um pesquisador não-dogmático. Acreditava que o avanço da psiquiatria se daria principalmente pelas investigações epidemiológicas e bioquímicas. Entretanto, ao lado dessa fé nas ciências empíricas e naturais, salientava que o psiquiatra brasileiro deveria, para viabilizar e enriquecer sua prática clínica, conhecer profundamente a realidade social e cultural de seus pacientes.

A conferência que aqui se apresenta, pode ser considerada uma amostra representativa do pensamento deste grande mestre. Nela, ele comenta sobre os variados aspectos da psiquiatria transcultural, dando ênfase às Síndromes Ligadas à Cultura (culture-bound syndromes) do meio brasileiro. Assim, ele discorre com elegância e sagacidade sobre as entidades nosológicas intrigantes tais como o calundu, a caruara, o banzo, o tangolomango e o mau-olhado. Relembraremos o mestre amazonense/baiano, aprendendo sobre as manifestações do adoecimento mental em nosso meio cultural.

\section{Aspectos da psiquiatria transcultural no meio baiano**}

"A psiquiatria transcultural corresponde a um setor dos estudos psiquiátricos que teve pioneiros antigos, sobretudo ao se considerar que com o nome de psiquiatria comparada*** Kraepelin, desde os fins do século XIX, iniciou as suas primeiras pesquisas. Entretanto, pode-se afirmar que só a partir daí esses estudos adquirem a amplitude que viriam a ter em nossos dias.

A esta altura, dentro da psiquiatria transcultural, incluem-se as pesquisas relativas à incidência de cada distúrbio mental nas suas relações com a cultura. Isto tem a ver com os conteúdos patoplásticos impressos pelas culturas tanto nas neuroses como nas psicoses, ou seja, o tema ou apresentação de determinadas psicoses, temas e apresentações específicos para cada cultura. Também no campo da psiquiatria transcultural incluem-se os tratamentos populares moldados pelas culturas e, nos últimos anos, as pesquisas relacionadas à possível diferença de sensibilidade dos pacientes psiquiátricos de certas culturas a

\footnotetext{
*Alarcon RD. Identidad de la Psiquiatria Latinoamericana. México: Singlo veintiuno editores; 1990.

**Conferência transcrita da fita magnética do "Programa de educação continuada da Associação Brasileira de Psiquiatria - ABP" Volume 1, nº 3, 1982

***Vergleichende Psychiatrie (Psiquiatria Comparada) é o termo utilizado por Kraepelin para seus estudos de campo realizados em 1904, em Java. Nestes estudos Kraepelin visava a validação transcultural de seu construto nosológico, a Dementia praecox (esquizofrenia), comparando pacientes de Java com pacientes da Alemanha.
} 
tratamentos farmacológicos sobre cuja eficácia não há qualquer dúvida nas culturas ditas ocidentais ou européias.

Uma variante da psiquiatria transcultural, que a esta altura provavelmente aspira uma individualidade, corresponde à chamada psiquiatria folclórica, ${ }^{*}$ isto é, o estudo das concepções (populares) sobre a etiologia e os tratamentos tais como são feitos pelas populações locais.

No Brasil, seguramente existiu um pioneiro da psiquiatria transcultural e ele foi contemporâneo das primeiras investigações de Kraepelin. Nina Rodrigues, o professor de medicina legal da Bahia, que estudou vários temas, sem dúvida absolutamente modelares, do que hoje se consideraria o conteúdo da psiquiatria transcultural. Entretanto, na literatura psiquiátrica geral, as investigações a respeito destes problemas são esparsas.

Só mais recentemente e, sobretudo, em nosso estado - a Bahia - tem crescido o interesse pela psiquiatria transcultural. Tal interesse talvez se deva pelo influxo das influências decorrentes de uma população de elevada miscigenação racial e de sincretismo religioso muito intenso.

O que se passa entre nós, seguramente, é que há freqüentemente problemas específicos na clínica e sobretudo nos serviços públicos a desafiarem o psiquiatra".

\section{Prof. Álvaro Rubim de Pinho}

(Após esta breve introdução, o Professor Rubim de Pinho responde às perguntas do entrevistador)

$\boldsymbol{P}$ - Professor Rubim de Pinho, o senhor poderia nos dizer qual o interesse para o psiquiatra brasileiro nos chamados estudos de psiquiatria transcultural?

$\mathbf{R}$ - Ao nosso ver, esse interesse é fundamental porque há muitos comportamentos, há muitas reações, muitas expressões da personalidade que decorrem de condicionamentos culturais, e o psiquiatra mal avisado seguramente as confunde com autênticos distúrbios mentais. Eu gostaria que a média dos psiquiatras brasileiros, e baianos em particular, tivesse a capacidade que têm as mães-de-santo mais hábeis e certos líderes espíritas para diferenciar aquilo que são fenômenos que eles consideram religiosos e nós consideramos culturais, mas que sem dúvida são diversos daquilo que está no conteúdo da psiquiatria tradicional. Claro que esses líderes religiosos erram, como nós os médicos também erramos, mas eles sabem freqüentemente diferençar aquilo que comportaria um tratamento natural, ou seja o tratamento médico, o tratamento da medicina formal e aquilo que são fenômenos sensíveis aos tratamentos da medicina informal. Nós, os médicos, em geral, temos a nossa formação específica, vendo a medicina acadêmica como aquela que nos ensina basicamente os fenômenos biológicos e encarando os distúrbios da saúde como situações que seriam idênticas em todas as pessoas e em todos os povos.

Entretanto, há algo que diferencia o tratamento da doença e o tratamento da pessoa do doente. A pessoa do doente, freqüentemente, pode beneficiar-se de tratamentos populares. De fato, muitas das situações que são levadas ao psiquiatra no nosso meio ou que vão aos serviços públicos psiquiátricos são mais sensíveis a tratamentos religiosos e populares do que a tratamentos da medicina formal.

$\boldsymbol{P}$ - Seria possivel a citação de problemas mais definidos, ou seja, quais são aquelas situações que mais conduzem a essas dificuldades?

$\mathbf{R}$ - Eu acho que sobretudo as situações decorrentes dos chamados estados de possessão. No Brasil, tradicionalmente, desde antes da descoberta pelos portugueses, já existiam determinadas situações, influenciadas por mitos, consideradas como possessões por animais. Isso, aliás, tem a ver com modelos que são internacionais. Mas nós temos ainda em nossos dias, em plena atuação, as situações de possessões por espíritos, as situações de possessões demoníacas e as situações de possessões por divindades. No caso das religiões de procedência africana isto corresponde à possessão pelos Orixás. O médico desavisado seguramente confunde o que é um distúrbio psiquiátrico com estes estados de possessão. E aquelas pessoas capazes de possessão durante os cultos religiosos são freqüentemente pessoas absolutamente normais na sua vida fora daqueles momentos. Não há razões para pensar que a possessão esteja a expressar qualquer indício de patologia mental.

\section{$\boldsymbol{P}$ - O senhor poderia nos relatar se existem, ou existiram, no Brasil, "psicoses da cultura nacional"?}

$\mathbf{R}$ - Presentemente, difícil seria dizer que há psicoses próprias da cultura ou das nossas sub-culturas.** Entretanto, em diferentes momentos históricos, tem havido certos quadros mentais que, seguramente, tiveram uma fisionomia bem própria e que têm sido específicos da nossa cultura. Vale a referência a que, ainda que em tempo colonial, os viajantes europeus aqui encontraram epidemias da chamada Malinconia, estados de tristeza epidêmicos que os padres Jesuítas tratavam à custa de métodos de persuasão. Os portugueses, provavelmente tendo recebido da Guiné este conceito, para cá trouxeram uma outra forma, uma outra vertente, uma outra feição disso - o Tangolomango. A noção do Tangolomango corresponde tradicionalmente aquela de um mal súbito que conduziria ao definhamento. É possível que nisso existissem fatores de ordem biológica, doenças somáticas agudas, mas também é possível que nisso estivessem estados de anormalidade mental aguda, sobretudo estados depressivos.

Há conceitos etiológicos populares que têm sido muito importantes para a população brasileira do Norte, sobretudo do extremo Norte e Nordeste, mas que também estiveram presentes na Bahia. O conceito Quebranto, por exemplo, como influ-

\footnotetext{
*Este é o termo preferido pelo pesquisador peruano Carlos Alberto Seguín, expoente da psiquiatria transcultural Latino-americana, que estudou os procedimentos terapêuticos da medicina indígena, e a quem Rubim de Pinho muito admirava.

**As Síndromes Ligadas à Cultura (Culture-bound Syndroms) são objeto da investigação psiquiátrica desde a segunda metade do século XX, com as descrições realizadas por viajantes e alienistas europeus, de quadros como Amok e Latah (Malásia), Koro (China), dhat (Índia), Pibloktoq (Comunidade esquimós árticas) Taijuin Kyofusho (Japão) e o Zar (Etiópia). Estas síndromes têm "obrigado" a psiquiatria ocidental a rever a questão da universalidade versus particularidade cultural de suas próprias entidades nosológicas. Rubim de Pinho procurou investigar durante toda a sua vida os aspectos descritivos e a significação histórica e clínica de alguns quadros comportamentais relacionados à cultura brasileira.
} 
ência (é duvidoso se de práticas mágicas ou de "miasmas"), conduzindo a uma sensibilidade maior das pessoas às doenças, inclusive às doenças mentais e a possíveis estados depressivos. Outro exemplo é o conceito do Olhado, provavelmente uma versão nacional correspondente àquilo que foi na Europa o chamado Magnetismo Animal, a possibilidade de influências magnéticas dos olhos de determinadas pessoas conduzindo ao comprometimento da saúde física e mental de outras pessoas.

Há, entretanto, alguns conceitos nosológicos que eu quero particularmente referir e estes são muito relacionados à Bahia. O Banzo teve, sem dúvida, uma presença nacional. Aprendemos com os historiadores que os negros importados da África traziam consigo, muitas vezes, a vocação para a tristeza. A partir da viagem até a chegada às nossas costas, apresentavam estados de definhamento, ficavam parados, e a própria expressão Banzo, suposta de procedência angolana, reflete seguramente uma nostalgia, uma saudade da terra. Diferentes estudiosos atribuíram interpretações diferentes às causas do Banzo. Entre eles, Satamínio Duarte, que pensava tratar-se de psicoses esquizofrênicas de tipo catatônico e Pirajá da Silva, que acreditava que fossem casos de doença do sono.

A partir de entrevistas que nós realizamos com pessoas idosas, que tinham recebido a transmissão de conhecimentos dos velhos do tempo de sua juventude, a impressão que nós temos é que a identificação do Banzo deve ter correspondido, rigorosamente, àquilo que ao tempo de guerra da década de 40 foi chamado Síndrome de Campo de Concentração. Havia um estado depressivo ao qual se superpunha toda a síndrome decorrente duma pluricarência alimentar; assim havia, da depressão, a anorexia que lhe era própria, mas havia, ao lado disso, realmente, fatores de ordem biológica dependentes da insuficiência de proteínas e provavelmente da insuficiência de fatores complementares do tipo vitamínico.

O Banzo, pelas descrições que nós assim obtivemos, sem dúvida indiretas, em geral ocorria nas longas viagens dos navios negreiros, com os escravos sujeitos ao trabalho forçados. A notícia que pudemos recolher é aquela de que, ao chegarem, ao menos aqui na Bahia à chamada Praia do Chega Negro (onde hoje está o aeroclube de Salvador), havia alguns que estavam caquéticos, próximos de morte, mas outros que se reanimavam apenas passados poucos dias ao contato da luz do sol e com outra alimentação, mesmo que continuada a situação de escravidão e mesmo que continuada a distância em relação à terra natal.

A pesquisa feita por Joildo Ataíde sobre as causas de morte dos escravos da Bahia no século XIX não revelou qualquer caso em que tivesse constado como motivo imediato da morte este diagnóstico, mas o Banzo seguramente já tinha terminado desde que terminaram as viagens. Os escravos aqui residentes, filhos de escravos, aqueles nascidos já em terra brasileira, ao que pare- ce, não apresentavam o Banzo e, apesar da discordância de Nina Rodrigues, há depoimentos apreciáveis no sentido de que, mesmo na condição de escravo, o preto africano aqui adquiria uma relativa acomodação no plano do bem estar pessoal.*

$\boldsymbol{P}$ - No Norte e Nordeste houve-se falar muito no chamado Calundu. $O$ que o senhor pode nos dizer a respeito deste fenômeno?

$\mathbf{R}$ - Outro conceito que não se pode dizer que corresponda a uma psicose, mas que seguramente corresponde a um fenômeno do âmbito psiquiátrico é o chamado Calundu. Os brasileiros do Norte e particularmente da Bahia se habituaram desde pequenos a ouvir em Calundu como correspondente a uma distimia irritável. Há determinadas pessoas que, em certos dias, diz-se assim, "já acordam com os seus calundus" - já acordam zangadas, sensíveis quanto a tudo que lhes acontece e, nestes dias, são evidentemente capazes de reações incomparavelmente mais agressivas do que o que acontece na média do seu humor normal.

Calundu foi também palavra usada com uma intenção de referir certos festins de pretos africanos, mas o Calundu no sentido de disforia, no sentido de distimia irritável, teve, diferentemente do Banzo, interpretação religiosa. Parece que, em nenhum momento, foi atribuída ao Banzo uma causa relacionada com castigos ou com influências de Orixás ou de diabos. Ao invés disto, o Calundu foi visto como um estado de possessão. Diferente dos outros estados de possessão, porque nos outros, como acontece habitualmente no Estado de Santo, há uma modificação imediata, uma modificação transitória da consciência quanto à identidade pessoal, enquanto que a pessoa com Calundu não sabe que está sendo possuída por essa divindade que a faz assim irritadiça.

$\boldsymbol{P}$ - Existe uma síndrome chamada Caruara** que deixa as pessoas sonolentas e sem forças, gostaria também que o senhor comentasse sobre essa psicose.

$\mathbf{R}$ - Quero referir um outro conceito nosológico, que foi bastante importante, a Caruara. Esta entidade caminhou na segunda metade do século passado do Maranhão até a Bahia, instalando-se sobretudo na cidade do Salvador e, mais particularmente, no Bairro de Itapajipe. As pessoas ficavam incapazes de se pôr em pé e de andar. Nina Rodrigues foi um dos grandes estudiosos do tema, identificando-a com a astasiaabasia histérica descrita por Charcot e por discípulos seus na Salpêtrière. A Caruara funcionava sob diferentes formas clínicas e era necessário ao médico, até o começo deste século na Bahia, fazer o diagnóstico diferencial entre Beribéri e Caruara sempre que as pessoas tinham incapacidade de movimentar os membros inferiores.

\footnotetext{
*Há certa controvérsia sobre isto. Nos relatos do naturalista alemão Von Martius, de 1844, este pesquisador descreve o Banzo tanto em negros escravos como em populações indígenas brasileiras nativas, mostrando que o Banzo não se restringia a negros recém-chegados de viagem nos navios negreiros. Ver nosso artigo sobre Von Martius na Revista Brasileira de Psiquiatria 1999;21(1):48-9.

**Em relação a Caruara, no interessante editorial da Revista Brasileira de Psiquiatria (“Ansiedade Antraz”, Rev Bras Psiquiatr 2001;23(4):175), Naomar de Almeida Filho propõe uma semelhança (real ou metafórica?) entre o estado de ansiedade coletiva desencadeado pelo atentado de 11 de setembro nos EUA e a "epidemia" de Caruara, na Bahia, em 1918. No livro "As coletividades anormais", Nina Rodrigues descreveu a epidemia de astasia-abasia coreiforme de origem psicogênica ou, mais propriamente, sociogênica (Rodrigues NR. As coletividades anormais. Ramos A, editor. Rio de Janeiro: Ed. Civilização Brasileira; 1939).
} 
Vale ainda um registro. Os que ainda estão vivos e que foram contemporâneos da Guerra de 1914 a 1919 sabem que, até esses tempos, existiu entre nós, com o nome de Diabo no Corpo, uma condição pela qual determinadas pessoas, quando agitadas, sobretudo do sexo feminino, eram levadas semanalmente à Igreja da Piedade para serem exorcizadas pelos frades capuchinhos. Tratava-se aí de algo de absoluta semelhança com as epidemias correspondentes à possessão de bruxas, à possessão demoníaca, que a Europa assistiu durante a Idade Média. Há dúvidas sobre os diagnósticos. Provavelmente não seria só histeria. É possível que outros doentes, inclusive bem psicóticos, quando agitados, fossem motivo desses tratamentos por exorcismos. Cabe pensar que, noutras regiões brasileiras, outras psicoses ou outros estados mentais caracterizados como anormais, tenham tido explicações populares ou tenham sido motivo de uma difusão no pensamento popular, tão específicos como a Bahia teve nestas situações.

Há também aspectos trans-históricos que, seguramente, merecem registro. É aqui perfeitamente cabível a paródia de uma frase tradicional: "A sociedade tem as doenças que merece!" Os momentos históricos comportaram, na dependência dos modelos para sugestão das massas, este ou aquele tipo de doença psíquica ou pelo menos este ou aquele tipo de comportamento caracterológico a merecer do psiquiatra uma apreciável atenção. Aquilo que eu gostaria de definir mais uma vez, como fecho desta palestra, é o fato de que o psiquiatra deve estar atento para tudo que, numa dita doença mental, é inclusão da cultura. O psiquiatra deve, portanto, estar bem vigilante para tudo aquilo que é expressão da cultura e não autêntica doença mental. 